Akten zur Auswärtigen Politik

der Bundesrepublik Deutschland

1961 


\section{Akten zur Auswärtigen Politik der Bundesrepublik Deutschland}

Herausgegeben im Auftrag des Auswärtigen Amts vom Institut für Zeitgeschichte

Hauptherausgeber

Andreas Wirsching

Mitherausgeber

Hélène Miard-Delacroix und Gregor Schöllgen 


\section{Akten zur Auswärtigen Politik der Bundesrepublik Deutschland

\author{
1961
}

Band I: 1. Januar bis 31. Mai 1961

Wissenschaftliche Leiterin

Ilse Dorothee Pautsch

Bearbeiter

Mechthild Lindemann und

Christoph Johannes Franzen 
ISBN 978-3-11-060423-8

e-ISBN (PDF) 978-3-11-060486-3

e-ISBN (EPUB) 978-3-11-060526-6

ISSN 2192-2454

Bibliografische Information der Deutschen Nationalbibliothek

Die Deutsche Nationalbibliothek verzeichnet diese Publikation in der Deutschen Nationalbibliografie; detaillierte bibliografische Daten sind im Internet über http://dnb.dnb.de abrufbar.

\section{Library of Congress Control Number: 2018960084}

(C) 2018 Walter de Gruyter GmbH Berlin/Boston

Druck und Bindung: Hubert \& Co. GmbH \& Co. KG, Göttingen

www.degruyter.com 